\title{
A GARANTIA CONSTITUCIONAL DO NEOLIBERALISMO
}

\author{
THE CONSTITUCIONAL GUARANTEE OF NEOLIBERALISM
}

\section{Kristian Rodrigo Pscheidt ${ }^{1}$}

SUMÁRIO: Introdução; 1 . Estado como instrumento de conformação; 1.1 O Direito e a Constituição; 2. A Constituição de 1988; 2.1 A base reacionária da Constituição; 2.2 Um direito constitucional reflexivo; 3 . 0 exemplo das agências reguladoras; 3.1 O bloqueio constitucional na consecução de políticas sociais; Considerações finais; Referências das fontes citadas;

\section{RESUMO}

O Estado, inegavelmente, é o principal elemento para a manutenção do sistema capitalista. É por meio dele que são traçadas políticas econômicas que encaminham a sociedade para seu desenvolvimento. Todavia, dentro de um sistema dinâmico, ora assume-se uma condição monopolista, ora delega-se sua atuação para entes privados.

O Estado é uma instituição que utiliza a Constituição de 1988 como ferramenta de regulação. Há uma nítida evolução social e a aptidão para a consecução de políticas de desenvolvimento sustentável. Porém, as bases liberais e individualistas continuam a calçar a atual Constituição. O neoliberalismo ataca com força intensa e ainda promove uma atividade voltada para a acumulação do capital.

Assim é possível perceber que há forças superiores e diferentes daquilo que o texto normativo preconiza. E se a prática mostra-se diferente daquilo que intenta o Legislador, qual sentido teria caucionar a sociedade sobre as Agências Reguladoras em seus estritos e minuciosos regulamentos?

A partir desta concepção é possível verificar que, ao direcionar o poder executivo para as agências reguladoras, exacerba-se um distanciamento ainda maior entre a realidade e as disposições da Constituição de 1988.

PALAVRAS-CHAVE: Estado Neoliberal, Constituição, Agências Reguladoras.

\footnotetext{
1 Professor dos cursos de graduação e pós-graduação em Direito pela Universidade Tuiuti do Paraná e da Faculdade CNEC Campo Largo, Doutorando e Mestre em Direito Político e Econômico pela Universidade Presbiteriana Mackenzie (2014), possui L.L.M em Direito de Negócios pela FMU (2014), é especialista em Direito Tributário pelo Centro Universitário Curitiba (2010), possui graduação em Direito pela Pontifícia Universidade Católica do Paraná (2008) e graduação em Jornalismo pela Pontifícia Universidade Católica do Paraná (2004). Rua Rogério Pereira de Camargo, 327, apto 27, Curitiba/PR, CEP 81280-390. kristian_adv@hotmail.com.
} 


\section{ABSTRACT}

The State is the main element for the maintenance of the capitalist system. With him, economic policies are drawn and direct the society to its development. However, in this dynamic system, sometimes assume a monopolistic condition, sometimes delegated to private entities their attributions.

The state is an institution that uses the Constitution as a tool of regulation. There is a clear social development to the achievement of sustainable development policies. But the liberal and individualistic bases continue to wear the current Constitution. Neoliberalism attacks with intense force and also promotes an activity geared to the accumulation of capital.

So you can see that there are forces greater and different from what the normative text proposed. And if the practice seems different from what the legislator intends, what sense would endorse the regulatory agencies in their strict and detailed regulations?

From this conception is possible to verify that the executive power to direct the regulatory agencies, is exacerbated an even greater gap between reality and the provisions of the 1988 Constitution.

KEYWORDS: Neoliberal State, Constitution, Regulatory Agencies.

\section{INTRODUÇÃO}

A história capitalista tem desvendado diversas concepções de Estado. Ora como centro imutável e superior de força (absolutismo), ora como negação de sua influência (liberalismo); sendo que atualmente se tentou envidar em um meio-termo (neoliberalismo), propugnado pela atuação do Estado por meio de agências reguladoras.

Esta dinâmica evidencia o Estado não como um dogma fixo, estável e indiferente às realidades sociais. Assim, mostra-se correta a afirmação de que o Estatuto Social do Estado, isto é, sua Constituição, deva refletir o contexto socioeconômico para possuir validade. Isso se verifica mais patente diante das grandes crises que o homem contemporâneo presenciou.

E neste contexto de crises, desde a década de 1970 que se fundamenta o papel do Estado sobre bases neoliberais, cujas ideias foram especialmente 
difundidas por Milton Friedman. Ultrapassa-se a noção de presença maciça e onipresente de John Maynard Keynes por uma noção de Estado regulador, acima, mas lateral as atividade econômica.

No Brasil, duas décadas depois, ocorre uma situação peculiar com a promulgação da Constituição de 1988. O Estado, pelo texto constitucional, deve ao mesmo tempo garantir uma série de direitos ao cidadão, enquanto que também está incumbida de propiciar à iniciativa privada que atue como elemento propulsor das atividades básicas.

Nesta concepção que se verifica a Constituição de 1988 como um mero engodo de forças superiores, inclusive ao próprio Estado, pois tudo permite. E se tudo permite, seria correto rotulá-la de dirigente, ordenadora ou propulsora de uma política Estatal? Os braços de atuação mais evidentes, que são as agências reguladoras, exercem um papel de imposição ou de mera conformação?

Isso porque, ao mesmo tempo em que a Constituição sugere uma atuação mais incisiva do Estado, quando ela é realizada, a própria Constituição impede que direitos se concretizem. É neste embate que o presente artigo pretende caminhar para que, de modo sintético, revelar se o papel da Constituição é incentivar ou restringir a atuação do Estado.

Para tanto, a análise seguirá pelo paradoxo da atuação das agências reguladoras, eis que de constituem como a expressão contemporânea mais evidente da política neoliberal estabelecida na macroeconomia mundial.

\section{ESTADO COMO INSTRUMENTO DE CONFORMAÇÃO}

A concepção de Estado vem sendo alterada e conformada com a realidade econômica desde a sua criação. A partir do século $X V$, quando é possível estabelecer os traços de uma instituição dissociada da pessoa do 
PSCHEIDT, Kristian Rodrigo. A garantia constitucional do Neoliberalismo. Revista Eletrônica Direito e Política, Programa de Pós-Graduação Stricto Sensu em Ciência Jurídica da UNIVALI, Itajaí, v.11, n.2, 2은 quadrimestre de 2016. Disponível em: www.univali.br/direitoepolitica - ISSN 1980-7791.

governante, ainda que subordinado a ele, é que se denota este ente como um instrumento de manutenção do sistema socioeconômico².

Afora as concepções ideológicas e sociológicas sobre o Estado3, não há como dissociar o conceito ao momento histórico do qual se origina, surgindo assim suas direções. O modelo absolutista surge como primeira expressão do Estado Moderno, na qual a monarquia absolutista se apropria na condição de proprietários dos meios e exercem seu império incontestável e divino sobre o território. Neste sentido, Lênio Luiz Streck ${ }^{4}$ afirma que "tal estratégia absolutista serviu fundamentalmente para, na passagem do modelo feudal para o moderno, assegurar a unidade territorial dos reinos, sustendo um dos elementos fundamentais de forma estatal moderna: o território".

Exaurida a noção absolutista, recrudescida pela realidade social, o contexto da Revolução Francesa de 1789 eclode uma mudança de concepção do modelo econômico e, imediatamente, a noção de Estado é subvertida. Surge o modelo contratualista, perpetrado nos séculos XVI a XVIII, que se apoia na ideia do fundamento do poder político a partir de um acordo de vontades, tácito ou expresso, que ponha fim ao estágio de natureza e dê início à sociedade civil, resplandecido a partir da razão

\footnotetext{
2 Nicolau Maquiavel é citado como precursor da noção moderna de Estado, isto é, como um ente diferenciado da pessoa do governante, relacionada a uma sociedade política dotada de certas características bem definidas. Dalmo de Abreu Dallari (Elementos de Teoria Geral do Estado. $2^{a}$ ed. São Paulo, Saraiva, 1998, p. 22) explica que "a denominação Estado (do latim status estar firme), significando situação permanente de convivência e ligada à sociedade política, aparece pela primeira vez em "O Príncipe" de MAQUIAVEL, escrito em 1513, passando a ser usada pelos italianos sempre ligada ao nome de uma cidade independente, como, por exemplo, stato di Firenze. Durante os séculos XVI e XVII a expressão foi sendo admitida em escritos franceses, ingleses e alemães. Na Espanha, até o século XVIII, aplicava-se também a denominação de estados a grandes propriedades rurais de domínio particular, cujos proprietários tinham poder jurisdicional".

3 Neste sentido Darcy Azambuja (Teoria Geral do Estado. Rio de Janeiro, Globo, 2000 , p. 2) conceitua o Estado como sendo "uma sociedade, pois se constitui essencialmente por um grupo de indivíduos unidos e organizados permanentemente para realizar objetivo comum".

${ }^{4}$ STRECK, Lênio Luiz. Ciência Política e Teoria Geral do Estado. $3^{a}$ Ed. Porto Alegre: Livraria do Advogado, 2003, p. 45.
} 
PSCHEIDT, Kristian Rodrigo. A garantia constitucional do Neoliberalismo. Revista Eletrônica Direito e Política, Programa de Pós-Graduação Stricto Sensu em Ciência Jurídica da UNIVALI, Itajaí, v.11, n.2, 2은 quadrimestre de 2016. Disponível em: www.univali.br/direitoepolitica - ISSN 1980-7791.

humana, legitimando a base do sistema jurídico. Os principais representantes desta corrente ficam a cargo de Thomas Hobbes ${ }^{5}$ e John Locke $^{6}$, cuja posição vem consolidada por Jean-Jacques Rosseau na ideia do pacto social?.

Calcado no individualismo, a visão contratualista de Estado é a essência do liberalismo, pois fixa a transição das relações grupais fixas pela autodeterminação individual. Neste cenário que Adam Smith ${ }^{8}$ consegue difundir a teoria econômica da "mão invisível", para quem o que importa "é dar liberdade de ação individual e limitar o papel do Estado à simples manutenção da ordem e segurança"'.

Assim o Estado Liberal serviu a ordem econômica até a estridente crise humanitária presenciada no início do século $X X$, alavancadas pela $1^{a}$ Guerra Mundial e, enfim, consolidada pelo crack da Bolsa de Nova Iorque de 1929. Agora, novamente, o Estado é alterado para uma concepção social, intervencionista e garantidora de funções básicas. Assume responsabilidades organizativas e diretivas do conjunto da economia, adotando-se a posição econômica de John Maynard Keynes ${ }^{10}$. O Estado

5 Cuja obra de maior destaque é o "Leviatã" (in Os pensadores. Trad. De João Paulo Monteiro. São Paulo, Abril Cultural, 1983).

6 Vide "Dois tratados sobre o governo" (Trad. Julio Fischer. São Paulo, Martins Fontes, 1998).

${ }^{7}$ Neste sentido o autor afirma que "cada um de nós põe em comum sua pessoa e todo o seu poder sob a suprema direção da vontade geral; e recebemos, enquanto corpo, cada membro como parte indivisível do todo". (O Contrato Social. Trad. Paulo Neves. Porto Alegre, LP\&M Pocket, 2010, p. 34)

8 Conforme ensina E. K Hunt (in História do Pensamento Econômico: uma perspectiva crítica. Trad. José Ricardo Brandão Azevedo. Rio de Janeiro, Elsevier, 2005, p. 41) sempre esteve na teoria de Adam Smith a ideia de que "embora os indivíduos pudessem agir de forma egoísta e estritamente em proveito próprio ou da classe à qual pertencessem, e muito embora o conflito individual e o conflito de classe parecessem, à primeira vista, resultar desses atos, havia, nas leis da natureza ou na divina providência, o que Smith chamava de mão invisível, que guiava esses atos, que aparentemente provocavam conflitos, de modo a haver mais harmonia".

${ }^{9}$ STRECK, Lenio Luiz. Ciência Política e Teoria Geral do Estado. $3^{a}$ Ed. Porto Alegre: Livraria do Advogado, 2003, p. 55

10 Para Keynes, a própria atividade estatal que, mesmo sem regulamentar a atividade particular, produzirá a distribuição dos resultados dessa maneira equitativa e compatível com o interesse coletivo. "De minha parte, acho que existe uma justificativa social e psicológica para as grandes desigualdades desde de renda e de riqueza, mas não para 
então se agiganta e assume o posto central dos meios de produção até a década de 1960, quando incessantes crises de crédito e a internacionalização da economia retiram a força hegemônica do Estado.

A crise do petróleo de 1979 é o marco final deste ciclo e, a partir de então, nasce uma a concepção neoliberal do Estado. Calcado sobre a visão de Milton Friedman sobre a economia, o Estado é novamente alterado para uma função menos atuante, e mais reguladora do mercado. O papel central é assegurar e promover ações que detém ao homem-trabalhador garantias para a obtenção, manutenção e execução do seu trabalho em condições dignas. Reduze-se o Estado para a manutenção do mercado visando provar que "sob todos os aspectos, econômicos e não econômicos, um sistema capitalista de livre mercado é o melhor de todos os mundos possíveis" como afirma E. K. Hunt ${ }^{11}$.

Portanto, a história demonstra que não é o Estado quem dita os passos do homem, mas tão somente conforma uma realidade criada e amoldada de acordo com a política macroeconômica vigente. É errado pensar que somente a alteração das diretrizes estatais será suficiente para garantir direitos, esplandecer o desenvolvimento ou marcar novas concepções de mercado.

Neste sentido a única concepção de Estado possível é aquela percebida por Joachim Hirsch ${ }^{12}$, que o enuncia não como sendo um instrumento aplicável para a obtenção de objetivos sociais arbitrários, "mas a expressão institucional de relações fundamentais de poder social, de

tão grandes disparidades como as que existem hoje. Existem atividades humanas valiosas que, para serem plenamente desenvolvidas, requerem a motivação de ganhar dinheiro e um ambiente onde exista a propriedade privada da riqueza. Além do mais, as inclinações humanas perigosas podem ser canalizadas pra fins relativamente inofensivos, dando-se aos homens oportunidades de ganhar dinheiro e ter riquezas" (The General Theory of Employment, Interest and Money. Nova Iorque: Harcourt Brace and World, 1936, p 374).

11 Hunt, E. K.. História do Pensamento Econômico: uma perspectiva crítica. Trad. José Ricardo Brandão Azevedo. Rio de Janeiro, Elsevier, 2005, p. 449

${ }_{12} \mathrm{HIRSCH}$, Joachim. Teoria Materialista do Estado. Trad. Luciano Cavini Martorano. São Paulo: Revan, 2010, p. 280. 
PSCHEIDT, Kristian Rodrigo. A garantia constitucional do Neoliberalismo. Revista Eletrônica Direito e Política, Programa de Pós-Graduação Stricto Sensu em Ciência Jurídica da UNIVALI, Itajaí, v.11, n.2, 2은 quadrimestre de 2016. Disponível em: www.univali.br/direitoepolitica - ISSN 1980-7791.

relações específicas de dominação e de exploração; ou seja, relações formadas com base nas classes e no gênero".

Entendido como instituição conformadora, pacificadora de conflitos e chave para o desenvolvimento capitalista, o modus operandi utilizado pelo Estado refletirá apenas a política econômica envidada pela classe dominante ${ }^{13}$. Neste papel instrumental, o Direito é a ferramenta de pacificação e organização do Estado.

\subsection{O DIREITO E A CONSTITUIÇÃO}

A visão contratualista do Estado atribui-Ihe uma ficção até então nunca vislumbrada, na qual o Estado passa a possuir uma personalidade própria, ganha vida e é concebido como um ente autônomo e com capacidade própria. Na visão de José Joaquim Gomes Canotilho ${ }^{14}$, trata-se do "conceito jurídico-material de Estado de direito que, como foi assinalado, associava a lei à ideia de justiça material e, de alguma forma, ao pensamento democrático (a lei como produto da vontade geral), seguiu-se um conceito de Estado de direito formal".

13 No mesmo sentido Dalmo de Abreu Dallari (Elementos de Teoria Geral do Estado. $2^{a}$ ed. São Paulo, Saraiva, 1998, p. 47) enuncia que "todo Estado implica um entrelaçamento de situações, de relações, de comportamentos, de justificativas, de objetivos, que compreende aspectos jurídicos, mas que contém, ao mesmo tempo, um indissociável conteúdo político".

${ }^{14}$ CANOTILHO, José Joaquim Gomes. Direito Constitucional. 6a Ed. Coimbra: Livraria Almedina, 1993, P. 353. Segue o autor explicando que "as funções políticas e sociais deste Estado de Direito formal têm sido salientadas: a) afirmação da burguesia, não como um conglomerado de indivíduos, mas como corpo político que, através do Estado de direito, visa não propriamente a emancipação burguesa perante o Estado mas o próprio fundamento burguês do Estado; b) através do Estado de direito formal, a burguesia assegura a distribuição conservadora dos bens existentes (institutos jurídicos dessa distribuição: propriedade privada, contrato, liberdade de profissão e de empresa), não permitindo a sua inversão no sentido de fins sociais; c) através do método jurídico exclui-se qualquer crítica intrínseca à ordem social e política existente; d) através da garantia de distanciação perante o Estado ocultava-se, consciente -mente, a possibilidade de concentração de poderes não estaduais (monopólios) e a desprotecção de camadas cada vez mais numerosas da população". 
Estipular personalidade jurídica é exacerbar uma íntima relação entre o Estado e o Direito. Trata-se de institutos uniformes, mas não idênticos ${ }^{15}$. Enquanto que o primeiro é a institucionalização de forças sociais dominantes e congruentes entre si, pela manutenção do sistema, o Direito é a ferramenta pela qual a atuação do Estado se precipita. Essa diferenciação é essencial para não repetir teorias que percebem a submissão do Estado às normas jurídicas, mormente o positivismo jurídico.

O positivismo jurídico, sob o império das leis, propugna como premissa "a conversão do Estado absoluto em Estado Constitucional; o poder já não é de pessoas, mas de leis. São as leis, e não as personalidades, que governam o ordenamento social e político. A legalidade é a máxima de valor supremo e se traduz com toda energia no texto dos Códigos e das Constituições"16.

Assim, o Direito passa a ser um conjunto de regras de regulação que importarão em comportamentos esperados, enquanto ordem desejável, de um falso "consenso dominante"17. A norma jurídica, representada pela sua Constituição, quer fazer parecer que seus dispositivos conformam o senso comum. E se a vontade do povo é expressa pela Lei, não há como contestá-la, legitimando o poder do Estado. Trata-se do raciocínio conformista do capitalismo, pois esta proposição garante a perenidade do sistema.

15 Por isso é equivocada a premissa difundida por Hans Kelsen de que o Estado é o próprio Direito. (in Teoria Geral do Direito e do Estado. Trad. Luis Carlos Borges. São Paulo: Martins Fontes, 2000.

${ }^{16}$ Segundo Paulo Bonavides. (in Teoria Geral do Estado. $8^{a}$ Ed. São Paulo: Malheiros, 2010, p. 43)

17 Neste sentido, discorrendo sobre a relação entre Estado e Direito, Georges Bordeau (O Estado. Trad. Maria Ermantina de Almeida Prado Galvão. São Paulo: Martins Fontes, 2005. p. 41) afirma que "a ideia de um conjunto de regras que, impondo-Ihes disciplina, orientarão os comportamentos individuais de tal sorte que se realize o futuro esperado. Essas são as regras de direito. É por essa razão que eu qualifico de ideia de direito a representação da ordem desejável que, em dada sociedade, constitui uma linha de força da mentalidade coletiva na qual ela cristaliza o consenso dominante". 
Nesta senda, o que se percebe é que o capitalismo utiliza-se de uma instituição independente (Estado) que, por meio de sua ferramenta jurídica, "garante uma estabilidade provisória transitória através da conformação de um modo de acumulação compatível com o modo de regulação"18. Assim, sucintamente, fixam-se as premissas teóricas e conceituais sobre a participação do Direito e do Estado na sociedade, que servirão de base para o desenvolvimento deste artigo, especialmente na identificação do papel exercido pelo Estado nas suas autarquias executivas, isto é, as agências reguladoras.

\section{A CONSTITUIÇÃO DE 1988}

Dentro desta retórica sobre o papel do Estado e do Direito, surge a Constituição de 1988 como principal conformador do Estado Capitalista Neoliberal. Redigida sob a égide de um projeto neoliberal, propôs-se "a desregulação, a libertação das atividades privadas sob regime especial"19. Como propugna Eros Roberto Grau20, "a ordem econômica na Constituição de 1988 define por opção um sistema, o sistema capitalista (...) que descrevo como modelo de bem-estar".

Os meios de produção operam sob o regime de empresa, que passa a ser o agente principal e continuam garantidos sob contratos privados em um mercado livre ${ }^{21}$. Enquanto os países passaram a competir pelos fluidos e voláteis capitais, financeiros ou produtivos disponíveis no mundo, em igualdade de condições com empresas transnacionais, há uma redução de

$18 \mathrm{HIRSCH}$, Joachim. Teoria Materialista do Estado. Trad. Luciano Cavini Martorano. São Paulo, Revan, 2010, p. 108

19 Ricardo Marcondes Martins. Regulação Administrativa à luz da Constituição Federal. São Paulo: Malheiros, 2011, p. 157.

20 A Ordem Econômica na Constituição de 1988. 13a Ed. São Paulo: Malheiros, 2008 , p. 348

${ }^{21}$ David Harvey (The limits do capital. Oxford, 1982, p. 96) enuncia que o capital não opera apenas no interior de um espaço socioeconômico homogêneo, mas de depara com contextos sociais diferentes politicamente, ou seja, com diversas estruturas de produção e relação de classe. 
gastos com a atuação direta do Estado22. Portanto, o papel do Estado subverteu-se não somente como garantidor de direitos, mas sim como um agente econômico perpetuador do mercado. É uma evolução do instituto.

É preciso evidenciar também que essa forma de atuação política somente poderia ser considerada eficaz e imparcial se o Estado detivesse soberania econômica ${ }^{23}$. A ultrapassada ideia de soberania ${ }^{24}$ como sendo a "entidade que não conhece superior na ordem externa nem igual na ordem interna" somente é eficaz a partir do momento em que remanescem meios (econômicos) para essa atitude de soberba. Por isso que é por meio da economia que um Estado firma sua posição de independência, sendo correto afirmar que uma nação dependente econômica e tecnologicamente não concretizará sua soberania política ${ }^{25}$.

A acepção é simples e de fácil constatação. Se a atuação políticoeconômica do Estado depender de qualquer fator exógeno, isto é, não inerente a si mesmo, certamente que qualquer atitude terá que ultrapassar este obstáculo. E sendo um objeto intransponível, a superação somente pode ocorrer por duas vias: pela força ou pela concessão (acordo). Em uma era de paz e harmonia de mercados, a primeira hipótese (militar) fica descartada; e remanesce a submissão ao capital, ou melhor, aos agentes econômicos dominantes.

\footnotetext{
22 "Todavia, há que sobrelevar que isso "não deve dar azo ao retorno a concepções abstencionistas do século XVIII (...) mas para torná-las (ações do Estado) mais inteligentes e menos onerosas aos cofres públicos", conforme Alexandre Santos Aragão (in Agências reguladoras. Rio de Janeiro, Forense, 2006, P. 71)

23 Vicente Bagnoli muito bem explica que uma nação somente poderá ser considerada soberana a partir do momento em possuir autonomia financeira. Enquanto a dependência de recursos financeiros persisitir, sempre ficará refém da vontade estrangeira. (Direito e Poder Econômico. São Paulo: Campus, 2008)

24 Propugnada por Jean Bodin na sua obra "Os Seis livros da República".

${ }^{25}$ Posição também adotada por NOBLE, Cláudio Luis da Silva. Soberania Econômica e a OMC. Boletim Jurídico, Uberaba/MG, a. 3, no 106. Disponível em: <http://www.boletimjuridico.com.br/doutrina/texto.asp?id=436>. Acesso em: 30 jun. 2016.
} 
Assim, a Constituição de 1988, enquanto ferramenta do Estado, se volta a manutenção deste cenário. Equivocam-se os juristas que vêm neste fenômeno a eliminação do mesmo ${ }^{26}$. Essa adequação amolda-se aos novos interesses capitalistas: primeiro pela garantia de fluidez do capital, depois pela abertura do mercado a setores antes monopolizados ${ }^{27}$.

Os contornos que o diferenciam do liberalismo clássico, por sua vez, são evidenciados pelo fenômeno da regulação, que atestam um mínimo de conformidade aos serviços básicos ${ }^{28}$. Isso porque não há como obter desenvolvimento sem pacificar as bases sociais. Os conflitos sociais devem estar apaziguados para que não haja a total ruptura do sistema. Como afirma Joachim Hirsch29, "um regime de acumulação estável só pode formar-se quando se impõe simultaneamente um contexto de regulação correspondente".

A regulação é o instrumento do Estado neoliberal que, "dependendo do caso concreto, pode lançar mão de instrumentos mais tradicionais, genéricos e coercitivos, ou de instrumentos de elaboração teórica e

26 Como fez José Eduardo Faria (O Direito na Economia Globalizada. $1^{a}$ Ed. São Paulo: Malheiros, 2004, p. 25) ao anunciar que "uma das facetas mais conhecidas desse processo de redifinição de soberania do Estado-nação é a fragilização de sua autoridade, o exaurimento do equilíbrio dos poderes e a perda de autonomia de seu aparato burocrático, o que é revelado pelo modo como se posiciona no confronto entre os distintos setores econômicos mais diretamente atingidos, em termos positivos ou negativos, pelo fenômeno da globalização".

27 Até mesmo Gilmar Mendes (Hermenêutica Constitucional e Direitos Fundamentais. Brasília: Jurídica, 2000, p. 40), ao defender os direitos humanos, enuncia que "afinal de contas, se as constituições pretendem ser - como efetivamente o são -, verdadeiros pactos entre gerações, parece intuitivo concluir que a sua preservação dependerá da possibilidade de virem a ser renovadas, pelo menos a cada geração, em todos os sentidos que possui a fecunda expressão renovar".

28 Neste sentido Paulo Otero (Vinculação e Liberdade de Conformação Jurídica do Sector Empresarial do Estado. Ed. Coimbra, 1998, p. 166) denota que "não há decisão válida de privatizar sem a prossecução directa e imediata de um interesse público. Desde logo, observando a constituição, pode dizer-se que o princípio da privatização tem subjacente o entendimento de que o interesse público na concretização do Estado de bem-estar não envolve sempre, ou, pelo menos, necessariamente, uma intervenção directa pública em termos econômicos, sendo possível de obter satisfação através da iniciativa econômica privada".

29 HIRSCH, Joachim. Teoria Materialista do Estado. Trad. Luciano Cavini Martorano. São Paulo, Revan, 2010, p. 108 
positiva mais recente, privilegiando a consensualidade e a comunicação com os agentes econômicos envolvidos, podendo ainda conciliar ambas as espécies" 30 .

No entanto, ainda que embutida em um contexto neoliberal, como enuncia Fabio Konder Comparato31, a Constituição de 1988 "continua a atribuir ao Estado, como não poderia deixar de ser, toda a gama de funções de transformação social, consagradas pelas Constituições pós-liberais do Século XX".

Agora, dentro deste modelo acima descrito, surge o questionamento principal do presente artigo: o Direito, concebido dentro de um modelo de Estado Neoliberal, a) impõe uma postura atuante para fins de garantia dos direitos sociais ou b) a Constituição serviria para assegurar a fluidez dos agentes econômicos?

\subsection{A BASE REACIONÁRIA DA CONSTITUIÇÃO}

A inefetividade de inúmeros dispositivos constitucionais tem uma relação direta com o modelo de hermenêutica jurídica que informa a atividade interpretativa da comunidade jurídica ${ }^{32}$. Mas não se trata de apenas uma crise hermenêutica. Karl Loewenstein ${ }^{33}$ explicita que "uma constituição é o que os detentores e destinatários de poder fazem dela na prática", isto é, a teoria da constituição deve se preocupar com a explicação realista do

\footnotetext{
${ }^{30}$ Conforme enuncia Alexandre Santos Aragão, Agências reguladoras. Rio de Janeiro, Forense, 2006, p. 84.

${ }^{31}$ COMPARATO, Fabio Konder. Planejar o Desenvolvimento: perspectiva institucional. Revista de Direito Público, no 88. São Paulo: RT, out/dez/1988, P. 18

32 Lenio Luiz Streck informa que "a complicada convivência do chamado Estado de Bemestar Social fica evidenciada pelo necessário recurso a novas categorias cognitivas da parte do intérprete". (in Hermenêutica jurídica em crise: uma exploração hermenêutica da construção do direito. Porto Alegre: Livraria do Advogado, 1999, P. 72)

33 LOEWENSTEIN, Karl. Teoría de la constitución, Traduzida para o espanhol por Alfredo Gallego Anabitarte. Barcelona: Ariel, 1964. pp. 205 e ss..
} 
papel que a constituição joga ou deveria jogar na dinâmica política ${ }^{34}$. Por isso que a Constituição de 1988 em nada alterou as estruturas clássicas do poder ${ }^{35}$. Continuam consagrados os institutos da proteção a propriedade privada (artigo 170, II), separação dos poderes (artigos $2^{\circ} \mathrm{e}$ $60, \S 4^{\circ}, \mathrm{III}$ ), os princípios republicanos e federalistas (artigo $1^{\circ}$ ), presidencialismo (artigo 76), livre iniciativa (artigo 10, IV), liberdade (artigo $5^{\circ}$ ), igualdade formal (artigo $5^{\circ}$ ), legalidade (artigo 50, II), entre outros.

Tome-se como exemplo o mito da separação de poderes, originado das predições de Montesquieu ${ }^{36}$, esboçados a partir de um momento individualista e racional do Estado Liberal, que limitam sensivelmente a atuação das esferas do Governo. Os predicados de Adam Smith ${ }^{37}$ (intervenção mínima) e da limitação dos poderes (Montesquieu) continuam sendo a base do texto constitucional e, sob essas premissas, apesar de conseguir impedir que o Estado faça o mal, também o impede de realizar conquistas. Por isso, apesar de maquiarem uma incessante busca de consolidação de direitos humanos, criam uma estrutura eficiente para impedir uma atuação incisiva do Estado.

34 Vide Gilberto Bercovici (in Soberania e Constituição: para uma crítica do constitucionalismo. São Paulo: Quartier Latin, 2008, p. 15)

35 Neste sentido ver Fabio Konder Comparato. Planejar o Desenvolvimento: perspectiva institucional. Revista de Direito Público, no 88. São Paulo: RT, out/dez/1988, P. 18

36 Montesquieu (Espírito das Leis. p. 33) funda sua teoria em como limitar o poder do Soberano, sendo nítido representante da aristocracia recém-formada. Por isso ele afirma que "no governo despótico, o poder passa por inteiro para as mãos daquele a quem foi dado. O vizir é o déspota em pessoa; e cada oficial particular é o vizir. No governo monárquico, o poder se aplica menos imediatamente; o monarca, quando o exerce, modera-o. Faz tal distribuição de sua autoridade, que nunca dá uma parte sem que tenha ficado com outra maior".

37 Adam Smith (Wealth of Nation, p. 21/22), afirma que "this great increase of the quantity of work which, in consequence of the division of labour, the same number of people are capable of performing, is owing to three different circumstances; first, to the increase of dexterity in every particular workman; secondly, to the saving of the time which is commonly lost in passing from one species of work to another; and lastly, to the invention of a great number of machines which facilitate and abridge labour, and enable one man to do the work of many". 
Nesta estrutura clássica, não cabe ao Estado desenvolver políticas ou programas de ação social a longo prazo. Pelo contrário, o constitucionalismo é um instrumento hábil a manutenção do sistema atual. Daí que doutrinadores como Alysson Leandro Mascaro ${ }^{38}$ e Gilberto Bercovici ${ }^{39}$ criticam a utilização do Estado de Direito pelas elites para moldar o rumo da economia de acordo com os interesses de mercado, e não vice-versa, isto é, o Povo definindo as políticas sociais e desenvolvimentistas.

Muito se fala sobre o que deveria ser concretizado, como faz Adolfo Gurreiri $^{40}$, que bem enuncia que "el Estado debía tener um importante papel, apliando su intervención para ocuparse de la redistribuición de los medios productivos - cuando la gestión ineficiente de las empresas privadas así ló consejara, como em la estructura agrária - y de lós ingresos, para aminorar la desigualdad social y lós problemas sociales y políticos que la misma provocaba". Todavia, as instituições atuais, calcadas em um Estado Liberal, tendem a "neutralização do poder público, num contexto social estático"41.

Por isso que a Administração Pública amoldou-se para "disciplinar, nos termos e para os fins da lei, os comportamentos dos particulares no campo das atividades que thes é próprio"42. Trata-se do conceito de administração ordenadora, em que o Estado se destina a organização da

\footnotetext{
38 Ver em a "Crítica da Legalidade e do Direito Brasileiro" (2aed São Paulo: Quartier Latin, 2001)

39 Ver em a "Soberania e Constituição: para uma crítica do constitucionalismo" (São Paulo: Quartier Latin, 2008)

${ }^{40}$ GURREIRI, Adolfo. Vigencia del Estado Planificador em la Crisis Actual. Revista de la Cepal, no 31, 1987, p. 203

41 Continua Fabio Konder Comparato (Planejar o Desenvolvimento: perspectiva institucional. Revista de Direito Público, no 88. São Paulo: RT, out/dez/1988, P. 31) que "os desvios e aberrações, quando ocorrentes, seriam casos individuais, incapazes de afetar a estrutura do todo coletivo. Os governantes, portanto, nesse esquema institucional, não tomam iniciativas nem empreendem políticas; eles administram os negócios correntes".

42 SUNDFELD, Carlos Ari. Direito Administrativo Ordenador. São Paulo: Malheiros, 1997, p. 20.
} 
vida privada dentro de uma relação genérica com a anuência do poder de autoridade, que passa a garantir a livre manifestação do poder econômico e repudiando qualquer intervenção na propriedade privada. Assegura-se a circulação do capital.

Deste modo, se a Constituição é referendada como um instrumento mutável de acordo com a política econômica vigente, na qualidade de ferramenta do Estado, não há como conceituá-la como sendo rígida e dirigente. O que ela propugna é uma ordenação das políticas públicas para fins de manutenção do sistema neoliberal ${ }^{43}$.

\subsection{UM DIREITO CONSTITUCIONAL REFLEXIVO}

Esse papel político da Constituição é esboçado por diversos indícios na sua forma de atuação. Tome-se como exemplo o fato de que o positivismo propugna uma supremacia cega e incondicional da Constituição ${ }^{44}$, procurando "imprimir ordem e conformação a realidade social"45. Trata-se do formalismo exacerbado e imutável das leis. Por esta linha de raciocínio, não haveria modos de alterar o alcance dos preceitos constitucionais. Todavia, são inúmeras as teorias que afastam essas premissas. Cria-se um arcabouço doutrinário que, quando exige-se a presença do Estado, ele é mitigado.

\footnotetext{
43 Miguel Reale (in Teoria do Direito e do Estado. 5a Ed. São Paulo: Saraiva, 2005, p. 348) enuncia que "o Direito, que exprime sempre uma subordinação de fatos a valores, concretiza-se em regras que são determinadas mediante diversas formas e modelos, daí resultando a procedência daquelas doutrinas que sustentam o pluralismo dos centros ou focos de juridicidade".

${ }^{44}$ Neste sentido está a Norma Hipotética Fundamental de Hans Kelsen (in Teoria Pura do Direito. Trad. João Baptista Machado. São Paulo: Martins Fontes, 1999).

45 Konrad Hesse. A força normativa da Constituição. Trad. Gilmar Mendes. Porto Alegre: Fabris, 1991, p 15.
} 
PSCHEIDT, Kristian Rodrigo. A garantia constitucional do Neoliberalismo. Revista Eletrônica Direito e Política, Programa de Pós-Graduação Stricto Sensu em Ciência Jurídica da UNIVALI, Itajaí, v.11, n.2, 2은 quadrimestre de 2016. Disponível em: www.univali.br/direitoepolitica - ISSN 1980-7791.

A construção de José Afonso da Silva ${ }^{46}$, referendada por Michel Temer ${ }^{47}$, acerca da eficácia das normas jurídicas é uma amostra da flexibilidade, em favor do neoliberalismo, dos preceitos constitucionais. Como é possível conceber que regras atinentes ao princípio da legalidade (art. 70, XI), proteção ao mercado de trabalho da mulher (art. 70, XX), repressão ao abuso de poder econômico (art. 173, §40), eliminação da concorrência, teto do funcionalismo público, entre outros exemplos, possuem eficácia limitada; ou ainda, possuam apenas conteúdo teleológico ${ }^{48}$ ?

Não fica longe do exemplo acima a doutrina acerca da reserva do possível, na qual a razoabilidade é evocada sempre que a prestação estatal interferir na existência de recursos materiais suficientes para a concretização do direito social ${ }^{49}$. Como que um mero pedaço de papel, concretizar os dispositivos da Constituição passam a depender de recursos financeiros e físicos do Estado50.

Mitigar o alcance dos preceitos constitucionais também é um dos papéis da função integradora dos princípios. Na limitação da intervenção do

${ }^{46}$ Segundo o autor, existem três tipos de normas: a) Eficácia plena, imediata e integral; b) Eficácia contida, imediata, direta mas não integral, pois a norma infraconstitucional poderá limitar sua aplicação; c) Eficácia limitada, que tem aplicabilidade reduzida e diferida para a edição de outra lei ou possuem apenas conteúdo teleológico. (DA SILVA, José Afonso. Aplicabilidade das normas constitucionais. $3^{a}$ Ed. São Paulo: Malheiros, 2007).

47 Que discorre sobre a eficácia jurídica e social das normas. Para ele, "a eficácia social se verifica na hipótese de a norma vigente, isto é, com potencialidade para regular determinadas relações, ser efetivamente aplicada a casos concretos. Eficácia jurídica, por sua vez, significa que a norma está apta a produzir efeitos jurídicos na medida em que a sua simples edição resulta na revogação de todas as normas anteriores que com ela conflitam". (In Elementos de Direito constitucional, p. 23)

48 Pedro Lenza elucida a diferença a cita ainda outros exemplos desta classificação, apostando inclusive que trata-se de posição referendada pelo Supremo Tribunal Federal (in Direito Constitucional Esquematizado. 13a. Ed. São Paulo: Saraiva, 2009, p. 139) 49 Ingo Wolfgang Sarlet cita a origem do instituto no Tribunal alemão, que entendeu que "(...) a prestação reclamada deve corresponder ao que o indivíduo pode razoavelmente exigir da sociedade, de tal sorte que, mesmo em dispondo o estado de recursos e tendo poder de disposição, não se pode falar em uma obrigação de prestar algo que não se mantenha nos limites do razoável". (in A eficácia dos direitos fundamentais. 2 ed. Porto Alegre: Livraria do Advogado, 2001. p. 265.)

50 Sobre a impossibilidade de concretização da dignidade da pessoa humana, vide Ana Paula Barcellos. (in A Eficácia Jurídica dos Princípios Constitucionais. O Princípio da Dignidade da Pessoa Humana. Rio de Janeiro e São Paulo: Renovar, 2002, p. 237.) 
Estado na propriedade, os princípios da irretroatividade, legalidade, tipicidade, razoabilidade são engessados e possuem força de uma norma direta e proibitiva. De outro viés, os princípios da proteção ao trabalho, igualdade, segurança, dignidade da pessoa humana, proteção a vida e saúde ganham contornos de normas delineadoras, genéricas e meramente hermenêuticas. Para alguns casos, como afirma Miguel Reale 51 , os princípios se "revestem de tamanha importância que o legislador lhes confere força de lei (...) mas a maioria apresentam contextos doutrinários ou são modelos dogmáticos fundamentais".

O próprio guardião da Constituição, o Supremo Tribunal Federal, angariou um modo de preterir a aplicação do texto constitucional, mesmo que reconhecida sua necessidade. Trata-se do art. 27, da Lei no 9.868/99, que prevê a possibilidade de aplicação de efeitos prospectivos da decisão judicial embasada na segurança jurídica ou de excepcional interesse social. Chancelam-se efeitos jurídicos a situações inconstitucionais com base em ideias, frequentemente, de cunho econômico ${ }^{52}$.

Por fim, não há como deixar de destacar que, em 24 anos de vigência, a Constituição Federal já passou por 70 (setenta) Emendas. Destas, apenas 4 (quatro) tiveram como objetivo elucidar, expandir ou garantir direitos sociais ${ }^{53}$, sendo que todas as demais foram inerentes a consecução de fins arrecadatórios, estruturais ou formais do Estado nacional.

\footnotetext{
51 Miguel Reale continua afirmando que "princípios gerais de direito são enunciações normativas de valor genérico, que condicionam e orientam a compreensão do ordenamento jurídico, quer para a sua aplicação e integração, quer para a elaboração de novas normas. Cobrem, desse modo, tanto o campo da pesquisa pura do Direito quanto o de sua atualização prática" (in Lições Preliminares de Direito. 25a Ed. São Paulo: Saraiva, 2001, p. 286).

52 Para justificar os efeitos prospectivos, Paulo de Barros Carvalho, evoca a segurança jurídica como um sobreprincípio, no qual as relações intersubjetivas se pautam, tendo em vista o planejamento de suas intenções judiciais, diante da certeza no modo de aplicação das normas jurídicas, que decorre de uma expectativa de conduta do Poder Público.(in Curso de Direito Tributário,. São Paulo: Saraiva, 2005, p. 150)

53 EC 26, de 14.2.2000, que alterou a redação do art. $6^{\circ}$ da Constituição Federal; a EC 28 , de 25.5.2000, que deu nova redação ao inciso XXIX do art. 7o e revoga o art. 233 da Constituição Federal; EC 64, de 4.2.2010, que alterou o art. $6^{\circ}$ da Constituição Federal,
} 
Portanto, não há como negar que a Constituição adota o princípio da liberdade de iniciativa econômica empresarial, que "enseja a reserva de um campo da atividade econômica a ser exercitado pela empresa privada. Dentro dele, em condições de liberdade regulamentada (...) movimentamse empresas privadas, no exercício da atividade econômica", como enuncia Eros Roberto Grau ${ }^{54}$. Esse é o escopo, a base e as premissas da Constituição de 1988.

Assegurar direitos sociais, garantir direitos fundamentais e prever a dignidade da pessoa humana estão presentes, mas não detém o centro das atenções da Carta Magna. O texto constitucional consolida o direito reflexivo procedente as relações negociais ${ }^{55}$, "outorgando ao Estado um papel de guia (e não direção) da sociedade". O direito passa a ser um instrumento que pode ser utilizado, e não que deve ser utilizado.

\section{O EXEMPLO DAS AGÊNCIAS REGULADORAS}

As agências reguladoras somam a função instrumental do Estado aliado ao papel coercitivo das normas jurídicas. Percebe-se que nada mais se consubstanciam que uma ferramenta jurídica para manutenção das políticas econômicas do Estado. O objetivo da agência reguladora não é (e nunca foi) a de garantir direitos humanos, níveis de satisfação dos consumidores ou um elevado grau de qualidade nos serviços (forma).

\footnotetext{
para introduzir a alimentação como direito social; e a EC 67, de 22.12.2010 que prorrogou, por tempo indeterminado, o prazo de vigência do Fundo de Combate e Erradicação da Pobreza.

54 GRAU, Eros Roberto. Elementos de Direito Econômico. São Paulo: Revista dos Tribunais, 1981. p. 83.

55 Neste sentido ver FARIA, José Eduardo. Direito e Globalização Econômica: implicações e perspectivas. São Paulo: Malheiros, 2010, p. 25
} 
Trata-se da manutenção do próprio sistema neoliberal (conteúdo), isto é, a rotação especulativa da realidade capitalista ${ }^{56}$.

O objetivo primordial é incrementar a concorrência, evitando atuações desleais e prejudiciais a sociedade. A ideia de garantia da competição é o núcleo da agência reguladora, fato este que pode ser percebido em todas as doutrinas especializadas no assunto, seja a nacional tais como Carlos Ari Sundfled ${ }^{57}$, Dinorá Adelaide Musetti Grotti ${ }^{58}$, Floriano Azevedo Marques Neto59, Ana Maria de Oliveira Nusdeo60, Ricardo Marcondes Martins ${ }^{61}$, entre outros; e especialmente a literatura estrangeira, como evidencia Johan den Hertog62 no seu estudo "Review of economic theories of regulation", elaborado em 2010, no qual destaca um rol extenso de pensadores americanos que atuam neste mesmo sentido. Dentre as definições, destaca-se aquela de Alexandre dos Santos Aragão63, que as define em consonância com o papel do Estado, isto é, criadas para "estimular a competitividade de suas economias, precisam se aliar com os interesses econômicos internacionais e serem bons moços na ordem internacional".

56 Realidade que no Brasil é ainda mais agravada em virtude da ausência total de soberania econômica do próprio Estado que as sustenta, pois o capital pertence as empresas estrangeiras.

57 SUNDFLED, Ari. Direito Administrativo Econômico. Coord. Carlos Ari Sundfeld. São Paulo: Malheiros, 2006, p. 18;

58 GROTTI, Adelaide Musetti. Teoria dos Serviços Públicos e sua transformação. In Direito Administrativo Econômico. Coord. Carlos Ari Sundfeld. São Paulo: Malheiros, 2006, p. 62;

59 MARQUES NETO, Floriano Azevedo. A nova regulação estatal e as agências independentes. In Direito Administrativo Econômico. Coord. Carlos Ari Sundfeld. São Paulo: Malheiros, 2006, p. 94;

60 NUSDEO, Ana Maria de Oliveira. A regulação e o direito da concorrência. In Direito Administrativo Econômico. Coord. Carlos Ari Sundfeld. São Paulo: Malheiros, 2006, p. 160;

61 MARTINS, Ricardo Marcondes. Regulação Administrativa a luz da Constituição Federal. São Paulo: Malheiros, 2011, p. 119.

62 HERTOG, Johan den. Utrecht School of Economics: Utrecht University, 2010.

63 ARAGÃO, Alexandre dos Santos. Agências reguladoras e a evolução do Direito

Econômico Administrativo. Rio de janeiro: Forense, 2006, p. 78. 
Não há como exigir que um ente mergulhado no capital seja independente e crie um cenário ideal de direitos e igualdades. Trata-se de um vício embrionário, no qual o Estado serve-se da economia, "preservando os interesses rentistas do estamento burocrático e de seus agregados, independentemente da classe social", nas palavras de Marcos Fernandes Gonçalves da Silva64. Não há como propugnar, como fez Marcos Augusto Perez ${ }^{65}$, que "as agências reguladoras são, em essência, organismos típicos do estado de bem-estar".

Dentro deste contexto, a forma de atuação (e limitação) dessas autarquias escancara que as premissas constitucionais nada mais se consubstanciam do que um trilho indicativo de como perseguir seus objetivos, atribuindo grande margem de calculabilidade, previsibilidade e limitação nos passos que envolvem a atuação regulatória do Estado, exatamente como almeja o capital neoliberal.

\subsection{O BLOQUEIO CONSTITUCIONAL NA CONSECUÇÃO DE POLÍTICAS SOCIAIS}

Não obstante o caráter instrumental das autarquias, seu modelo concorrencial e sua ótica capitalista, é fato que calcado em um contexto de bem-estar, deve a agência reguladora também intervir na consecução de serviços satisfatórios a sociedade. Esse é o papel formal estipulado para a regulação, pois "o Estado continua a exercer seu controle para que

\footnotetext{
64 O autor complementa que "no Brasil existe um cisão entre o público e o privado no momento da produção do bem público (...). Tal cisão é conveniente, num certo sentido, entre o público e privado, assim como a promiscuidade entre tais esferas também o é." (Formação Econômica do Brasil: uma reinterpretação contemporânea. Rio de janeiro: Elselvier, 2012. p. 123)

65 PEREZ, Marcos Augusto. As Agências Reguladoras no Direito Brasileiro: origem, natureza e função. Revista Trimestral de Direito Público, RTDP, 23/125.
} 
PSCHEIDT, Kristian Rodrigo. A garantia constitucional do Neoliberalismo. Revista Eletrônica Direito e Política, Programa de Pós-Graduação Stricto Sensu em Ciência Jurídica da UNIVALI, Itajaí, v.11, n.2, 2은 quadrimestre de 2016. Disponível em: www.univali.br/direitoepolitica - ISSN 1980-7791.

os serviços públicos ali desenvolvidos não fujam da qualidade pretendida"66.

Veja-se que a Agência Nacional de Saúde Suplementar, criada pela Lei 9.961/2000, possui competências tais como estabelecer, autorizar, avaliar, expedir, proceder, fiscalizar, monitorar, decidir, deliberar, fixar, propor, elaborar, adotar, instituir, penalizar, zelar, celebrar, (o artigo $4^{\circ}$ da referida Lei). A Agência Nacional de Telecomunicações (Lei 9.472/1996) também indica um extenso rol de capacidades, tais como (art. $2^{\circ}$ ) garantir, estimular, adotar, fortalecer, criar. A Agência Nacional de Energia Elétrica (Lei 9.472/1996, por sua vez, está habilitada a (art. 30) implementar, promover, gerir, dirimir, fixar, articular, estabelecer, zelar, sancionar, aprovar, homologar, regular, definir, etc. Por fim, a Agência Nacional de Petróleo (Lei 9.478/1997) tem como competências (art. $1^{\circ}$ ) preservar, promover, proteger, garantir, incrementar, identificar, utilizar, atrair, ampliar, incentivar, promover, fomentar, mitigar, etc.

Mas se a norma infraconstitucional permite tamanha capacidade de atuação das autarquias, por que seu papel mostra-se ainda incipiente na consecução de fins sociais? ${ }^{67}$ Porque a própria Constituição não permite uma atuação mais estridente, e impede uma intervenção incisiva na esfera das empresas privadas, pois sua estrutura ainda é calcada em bases liberais de limitação do poder Estatal.

66 Conforme lições de Roberto Luiz Ribeiro Direito Econômico Brasileiro - Uma visão didática. 1. ed. Goiânia-Goiás: Kelps, 2008. p. 82

67 Neste sentido, ver Eli Diniz e Renato Borschi, que enunciam que "num plano mais geral, nossa análise revela uma das maneiras contemporâneas em que sistemas de representação de interesses se entrecruzam com sistemas de representação política. $\mathrm{Na}$ medida em que tal entrecruzamento resulta de características impressas no padrão preexistente de diferenciação da estrutura de representação de interesses e sua articulação com o Estado, observa-se nada mais que a emergência do velho". (Empresários e Poder Legislativo no Brasil Contemporâneo. Trabalho apresentado no XXIV Encontro Anual da ANPOCS. Outubro 2000) 
PSCHEIDT, Kristian Rodrigo. A garantia constitucional do Neoliberalismo. Revista Eletrônica Direito e Política, Programa de Pós-Graduação Stricto Sensu em Ciência Jurídica da UNIVALI, Itajaí, v.11, n.2, 2은 quadrimestre de 2016. Disponível em: www.univali.br/direitoepolitica - ISSN 1980-7791.

É consabido que a uma norma68, para fins de aplicação, somente será dotada de efetividade se possuir um instrumento sancionatório. É um corolário fundamental para a prescritividade dos regramentos e a consequente obediência aos seus ditames. Sabedor desta conjectura, os agentes públicos prescrevem uma enormidade de penalidades e sanções em suas diversas resolução e decisões colegiadas.

Todavia, uma vez imposta a penalidade, os agentes econômicos privados valem-se primordialmente da própria Constituição para afastar sua aplicação69. Eis aí o paradoxo. A Constituição, que propugna o bem-estar, é alavancada contra o próprio Estado para impedir que seus fins sociais sejam almejados ${ }^{70}$. E as normas evocadas não mais denotam caráter programático, principiológico, hermenêutico ou indicativo, mas sim de cogência e aplicação imediata ${ }^{71}$.

Especificamente no caso das sanções, a doutrina de Fábio Medina Osório72 é peremptória ao enunciar que o Estado deve obediência a todos os princípios e proteções do Direito Penal, tanto é que no direito comparado

68 Conforme enuncia Norberto Bobbio, "somos inclinados a considerar um ordenamento tão mais jurídico (o Estado de direito é um Estado no qual o controle jurídico foi se ampliando, e por isso é mais jurídico do que um Estado de Polícia) quanto mais a técnica da sanção vai se aperfeiçoando".(in Teoria da Norma Jurídica. Trad. Fernando Pavan Baptista. São Paulo: Edipro, 2001, p. 145)

69 Maria Sylvia Zanella Di Pietro enuncia que "tipicidade é o atributo pelo qual o ato administrativo deve corresponder a figuras definidas previamente pela lei como aptas a produzir determinados resultados" (in Direito Administrativo. 21a ed.São Paulo: Atlas, 2007. P. 190.)

$70 \mathrm{Na}$ doutrina de José Afonso da Silva, "os administradores não podem exigir qualquer ação, nem impor qualquer abstenção, nem mandar tampouco proibir nada aos administrados, senão em virtude de lei" (in Curso de direito constitucional positivo. 18. ed. São Paulo: Malheiros, 2000, p. 423).

71 Toma-se como exemplo as afirmações de Celso Antonio Bandeira de Mello, ao enunciar que a "administração não poderá proibir ou impor comportamento algum a terceiro, salvo se estiver previamente embasada em determinada lei que lhe faculte proibir ou impor algo a quem quer que seja. Vale dizer, não lhe é possível expedir um regulamento, instrução, resolução, portaria ou seja lá que ato for para coartar a liberdade dos administrados, salvo se em lei já existir delineada a contenção ou imposição que o ato administrativo venha a minudenciar". (in Curso de direito administrativo. 18 ed. São Paulo: Malheiros, 2005).

72 OSÓRIO, Fábio Medina. Direito Administrativo Sancionador. 4a. Ed. São Paulo: RT, 2011, p. 149 
Europeu, em especial a Espanha, fala-se na unicidade de ambos institutos. Para o autor, "é necessário reconhecer que, no campo constitucional, cláusulas comuns ao Direito Público Punitivo, não como ramo jurídico, mas como aquele conjunto de normas que disciplinam as várias manifestações punitivas do Estado".

Outro exemplo marcante é a separação dos poderes. A Constituição de 1988 incrusta regra no artigo 50, XXXV que "a lei não excluirá da apreciação do Poder Judiciário lesão ou ameaça a direito". Essa inafastabilidade do Poder judiciário consolida, também, que toda vontade incisiva da agência reguladora em impedir a atuação do agente econômica poderá ser, sumariamente, alterada. Novamente, a Constituição será avocada, pelo seu anverso, para garantir a perenidade da propriedade privada e a livre iniciativa ${ }^{73}$.

Verifica-se deste modo que a regulação surge da harmonização de instituições e processos relativamente independentes, mas não alteram o conteúdo básico do sistema. O liberalismo econômico é chancelado e garantido. As concepções sociais, "ainda que não tenham um sujeito dirigente, entretanto conta com o Estado enquanto centro institucional, porque o poder de coerção física é fundamental para a manutenção das relações de classe, de suas formas sociais e dos modos de expressão institucionais" 74 .

Há um distanciamento entre aquilo que se propugna a realizar com aquilo que efetivamente concretiza. A interpenetração entre privado e público, bem como a emergência de uma infinidade de instância de decisões

73 Como enuncia Celso Ribeiro Bastos, "a atividade dos órgãos do Estado destinada a formular e atuar praticamente a regra jurídica concreta que, segundo o direito vigente, disciplina determinada situação jurídica". Por força de dispositivo constitucional, no Brasil essa atividade é privativa do Poder Judiciário, único órgão apto a formular decisões dotadas da força da coisa julgada". (in Comentários à Constituição do Brasil. São Paulo: Saraiva, 1989, p. 169)

74 Conforme HIRSCH, Joachim. Teoria Materialista do Estado. Trad. Luciano Cavini Martorano. São Paulo, Revan, 2010, p. 109. 
entram em concorrência com os demais aparelhos de controle estatal, inibindo uma atuação condizente com os predicados do bem estar, mas alinhados com as exigências do mercado ${ }^{75}$. A consequência, como se verifica, é uma diferença ainda mais da realidade dos fatos e o que faz parecer a lei estatal.

\section{CONSIDERAÇÕES FINAIS}

Não são poucos aqueles que propugnam o caráter moderno, atual e contemporâneo da Constituição de 1988, evidenciando seu lado humanista, social e em consonância com os direitos do ser humano; e há que se reconhecer que foram introduzidos elementos que formalizam a função social dos meios de produção e o desenvolvimento sustentável do Estado. Porém, poucos se lembram de que a estrutura do texto constitucional continua calcada em bases liberais e individualistas, retrógradas e compromissadas na manutenção do sistema capitalista. Neste paradoxo percebe-se uma nítida oposição de interesses.

Os meios de comunicação, as academias e os tribunais explicitam a profusão de uma corrente compromissada com o exercício dos direitos que assegurem a dignidade da pessoa humana, afastando-se o caráter reflexivo do Direito. Mas é isso que tem ocorrido na prática? Não, a realidade tem demonstrado exatamente o contrário.

É fato que as grandes teorias alicerçadas nos últimos anos no Direito têm evidenciado a garantia da propriedade em detrimento aos direitos de

\footnotetext{
75 Neste sentido Andre Noel Roth explica que "o direito reflexivo é um trabalho sobre princípios racionais e destinado a receber uma aplicação universal, das práticas jurídicas que resultam das relações de força entre interesses políticos e sociais antagônicos e contraditórios. Formatação essa que permite e legitima o desenvolvimento de um Estado fagocitado por uma regulação social condicionada por valores e interesses privados erigidos para o bem público". (in Direito e Globalização Econômica: implicações e perspectivas. P. 25)
} 
segunda ou terceira dimensão. Isso porque o Estado, enquanto instituição complexa de regulação, fomenta a Constituição como ferramenta para a manutenção de sua política socioeconômica.

E neste viés sistêmico, há que se garantir a circulação do capital, assim como tem sido realizado desde o século XVIII com o Estado Liberal. A separação dos poderes, as teorias sobre a eficácia da norma, as alterações constitucionais são exemplos de como a rigidez do texto legal é mutável e adequado conforme a realidade econômica.

Em tempos contemporâneos, neoliberais, comprova-se a manutenção das bases do sistema econômico de circulação de capitais por meios das agências reguladoras. Faz-se parecer na sua criação um objetivo social, com a consecução de direitos e satisfação da sociedade, mas o bojo desta atividade estatal está no fomento da competição, sendo que os anseios humanitários encontram limites na própria Constituição,

Assim, na via reversa, os instrumentos constitucionais de garantia da propriedade, livre iniciativa, liberdade de circulação e acumulação, apropriação dos meios de produção possuem força cogente, imediata e oponível a qualquer momento contra o Estado intervencionista. Portanto, a todo o momento, mais do que enfrentar os agentes econômicos, a sociedade está diante de um sistema estanque, ainda liberal, cujo desenvolvimento social apenas mascara a manutenção de um modo de exploração e acumulação do trabalho assalariado.

\section{REFERÊNCIAS DAS FONTES CITADAS}

ARAGÃO, Alexandre Santos. Alexandre Santos Aragão. Agências reguladoras. Rio de Janeiro, Forense, 2006;

AZAMBUJA Darcy. Teoria Geral do Estado. Rio de Janeiro, Globo, 2000;

BAGNOLI, Vicente. Direito e Poder Econômico. São Paulo: Campus, 2008; 
BARROSO, Luiz Roberto. Direito Econômico Brasileiro - Uma visão didática. 1. ed. Goiânia-Goiás: Kelps, 2008;

BASTOS, Celso Ribeiro. Comentários à Constituição do Brasil. São Paulo: Saraiva, 1989;

BERCOVICI, Gilberto. Soberania e Constituição: para uma crítica do constitucionalismo. São Paulo: Quartier Latin, 2008;

BOBBIO, Norberto. Teoria da Norma Jurídica. Trad. Fernando Pavan Baptista. São Paulo: Edipro, 2001;

BONAVIDES, Paulo. Teoria Geral do Estado. $8^{a}$ Ed. São Paulo: Malheiros, 2010;

BORDEAU, Georges. O Estado. Trad. Maria Ermantina de Almeida Prado Galvão. São Paulo: Martins Fontes, 2005;

CARVALHO, Paulo de Barros. Curso de Direito Tributário. São Paulo: Saraiva, 2005;

COMPARATO, Fabio Konder. Planejar o Desenvolvimento: perspectiva institucional. Revista de Direito Público, no 88. São Paulo: RT, out/dez/1988;

DALLARI, Dalmo de Abreu. Elementos de Teoria Geral do Estado. $2^{a}$ ed. São Paulo, Saraiva, 1998;

DI PIETRO, Maria Sylvia Zanella. Direito Administrativo. $21^{\text {a }}$ ed. São Paulo: Atlas, 2007;

FARIA, José Eduardo. O Direito na Economia Globalizada. $1^{a}$ Ed. São Paulo: Malheiros, 2004;

Direito e Globalização Econômica: implicações e perspectivas. São Paulo: Malheiros, 2010;

GRAU, Eros Roberto. A Ordem Econômica na Constituição de 1988. 13a Ed. São Paulo: Malheiros, 2008;

Revista dos Tribunais, 1981 ;

Elementos de Direito Econômico. São Paulo:

GURRIERI, Adolfo. Vigencia del Estado Planificador em la Crisis Actual. Revista de la Cepal, nº 31, 1987; 
HARVEY, David. The limits to capital. Oxford, 1982;

HESSE, Konrad. A força normativa da Constituição. Trad. Gilmar Mendes. Porto Alegre: Fabris, 1991;

HERTOG, Johan den. Review of economic theories of regulation. Utrecht School of Economics: Utrecht University, 2010;

HIRSCH, Joachim. Teoria Materialista do Estado. Trad. Luciano Cavini Martorano. São Paulo, Revan, 2010;

HOBBES, Thomas. Leviatã. In Os pensadores. Trad. De João Paulo Monteiro. São Paulo, Abril Cultural, 1983;

HUNT, E. K. História do Pensamento Econômico: uma perspectiva crítica. Trad. José Ricardo Brandão Azevedo. Rio de Janeiro, Elsevier, 2005;

KELSEN Hans. Teoria Geral do Direito e do Estado. Trad. Luis Carlos Borges. São Paulo: Martins Fontes, 2000;

. Teoria Pura do Direito. Trad. João Baptista Machado. São

Paulo: Martins Fontes, 1999;

KEYNES, John Maynard. The General Theory of Employment, Interest and Money. Nova Iorque: Harcourt Brace and World, 1936;

LOCKE, John. Dois tratados sobre o governo. Trad. Julio Fischer. São Paulo, Martins Fontes, 1998;

LOEWENSTEIN, Karl. Teoría de la constitución. Traduzida para o espanhol por Alfredo Gallego Anabitarte. Barcelona: Ariel, 1964;

MASCARO, Alysson Leandro. Crítica da Legalidade e do Direito Brasileiro. 2aed São Paulo: Quartier Latin, 2001;

MARTINS, Ricardo Marcondes. Regulação Administrativa à luz da Constituição Federal. São Paulo: Malheiros, 2011;

MELLO, Celso Antonio Bandeira de. Curso de direito administrativo. 18 ed. São Paulo: Malheiros, 2005;

MENDES, Gilmar. Gilmar Mendes. Hermenêutica Constitucional e Direitos Fundamentais. Brasília: Jurídica, 2000;

OSÓRIO, Fabio Medina. Direito Administrativo Sancionador. 4a. Ed. São Paulo: RT, 2011; 
OTERO, Paulo. Vinculação e Liberdade de Conformação Jurídica do Sector Empresarial do Estado. Ed. Coimbra, 1998;

PEREZ, Marcos Augusto. As Agências Reguladoras no Direito Brasileiro: origem, natureza e função. Revista Trimestral de Direito Público, RTDP, Ed. 23;

REALE, Miguel. Teoria do Direito e do Estado. 5a Ed. São Paulo: Saraiva, 2005;

Saraiva, 2001;

Lições Preliminares de Direito. 25a Ed. São Paulo:

ROSSEAU, Jean-Jacques. O Contrato Social. Trad. Paulo Neves. Porto Alegre, LP\&M Pocket, 2010;

SILVA, José Afonso da. Curso de direito constitucional positivo. 18. ed. São Paulo: Malheiros, 2000;

SILVA, Marcos Fernandes Gonçalves. Formação Econômica do Brasil: uma reinterpretação contemporânea. Rio de janeiro: Elselvier, 2012;

SMITH, Adam. Wealth of Nation. London: Electric Book, 1998;

STRECK, Lênio Luiz. Ciência Política e Teoria Geral do Estado. $3^{a}$ Ed. Porto Alegre: Livraria do Advogado, 2003;

- Hermenêutica jurídica em crise: uma exploração hermenêutica da construção do direito. Porto Alegre: Livraria do Advogado, 1999;

SUNDFELD, Carlos Ari. Direito Administrativo Ordenador. São Paulo: Malheiros, 1997;

Malheiros, 2006;

. et al. Direito Administrativo Econômico. São Paulo:

TEMER, Michel. Elementos de Direito Econômico. São Paulo: Revista dos Tribunais, 1981.

Submetido em: Outubro de 2015.

Aprovado em: Junho de 2016. 